\title{
Research on the Ecological Packaging Design Pattern of the Local Agricultural Products in Eastern Hubei Based on E-commerce Platform
}

\author{
Dan Wang \\ Huanggang Normal University \\ Huanggang, China 438000
}

\begin{abstract}
With the rapid development of the internet, the problems of high pollution and high consumables in the packaging of the eastern Hubei local agricultural products under the e-commerce mode is becoming more and more serious, which greatly influences the further development of the brand. Based on the principle of ecological packaging design, this paper puts forward that a systematic design shall be performed for the e-commerce products, and the packaging design shall adopt the generalized ecological packaging design pattern that is function-oriented with the concise and precise visual information expression technique, so as to reduce environment pollution, improve the utilization rate of the resources and enhance the brand popularity.
\end{abstract}

Keywords-e-commerce in eastern Hubei; local agricultural product; ecological package; design pattern

\section{INTRODUCTION}

The development of the e-commerce industry has led to the development of agriculture, however, the current situation of high pollution and high consumables of the sales packaging and logistics packaging of the ecommerce products goes against the natural and ecological green idea of agricultural products. In order to make the local agricultural products brands have a long-term development and the e-commerce of local agricultural products has an operating environment of a virtuous cycle, a kind of ecological packag ing design pattern shall be established, so as to reduce the consumption and waste of resources and reduce the environment pollution, so that the e-commerce local agricultural products industry can better take the road of sustainable development.

\section{THE DEVELOPMENT SITUATION OF THE E-COMMERCE LOCAL AGRICULTURAL PRODUCTS IN EASTERN HUBEI}

Eastern Hubei is known as "Dabie Mountain granary", especially Huanggang area which has produced many famous local products with distinctive features and complete categories, there are 40 national geographical protection products alone, which is the highest among the prefectural and municipal areas across the country, and among them the

Fund program: the youth project of the humanities and social sciences of Hubei education department in 2017 (No.: 17Q1 82) most famous products are the tea leaf, radix platycodi, chestnut, sweet persimmon, medicinal materials, vermicelli, peanut, sun-cured tobacco in Northern mountain areas and the lotus root, turnip, wine, Chinese yam, chili, garlic in the southern areas along the rivers and lakes [1]. Since 2015, the ecommerce of the eastern Hubei local agricultural products has been gaining mo mentu $\mathrm{m}$ with the great support of the provincial and municipal governments, according to statistics, the annual turnover of e-commerce in eastern Hubei area exceeded 40 billion yuan in 2015 , and the online retail transaction volume was nearly 6 billion yuan, accounting for about $3.4 \%$ of the total retail sales of the consumer goods in the city, which double from the previous year. The rapid development of e-commerce has driven the rapid growth of the local agricultural products economy in eastern Hubei. The main e-commerce sales models of eastern Hubei local agricultural products are "retail model", "Suichang model", "b2b model" and "b2b model", which has already established online distribution platforms on many shopping sites such as Nongcunwei, Taobao Huanggang division, Jingdong Huanggang division, No. 1 shop Huanggang division, Suning Huanggang division and Alibaba Huanggang division, etc. The e-commerce centers have been established in various counties and cities, which sell the local agricultural products online and offline.

The sales of large quantities of agricultural products also promote the development of packaging industry and have a great impact on the traditional packaging model. Due to lack of brand awareness, by far many high-quality local agricultural products in Huanggang are difficult to sell and make profits, the pricing power and the disclosure right is squeezed and diluted, which led to the lack of competitiveness in the online business community in China.

\section{ThE PROBlems EXISTING IN THE PACKAGING OF EASTERN HUBEI E-COMMERCE PRODUCTS}

The development of e-commerce has a great impact on the traditional packaging model, due to the changes of the shopping mode and the sales platform, the sales mode changed from previous retail to online sales, and the function of the packaging design is also changed from promotion function to circulation function and protection function, with the sales function as the auxiliary function. In 
this process, the promotion function of the packaging is weakened, and the promotion of the commodities is mainly completed by the website, the online packaging effect picture, the pictures, the videos, the $3 \mathrm{D}$ animation, etc, the protection function of the transportation packages is strengthened, so the commodities are wrapped in layers of packages when transported, which will become waste afterwards, the large quantities of transportation packages not only cause a great waste of the resources but also become the main source of the household garbage in people's daily life.

From the big trends, in the context of the ecommerce generated under the whole packaging industry and the "internet + " new business mode, the sales channels are increasingly diversified and three-dimensional, which undoubtedly brings vitality to the traditional industries and further expands the market space. However, the phenomena of excessive imitation, roughness, environmentally unfriendliness existing in the packaging design of eastern Hubei agricultural products have impeded the long-term development of the eastern Hubei e-commerce. This requires the designer to be able to seek a kind of packaging design pattern that meets the needs of e-commerce development combined with the characteristics of the ecommerce agricultural products and the function and development trend of the e-commerce products packaging, which will have an important role in various as pects such as saving cost and resources, enhancing product brand image, increasing product added value and bring good user experience to consumers.

\section{DISCUSSION ON THE ECOLOGICAL PACKAGING DESIGN PATTERN OF EASTERN HUBEI E-COMMERCE PRODUCTS}

\section{A. Systematic Packaging Design Pattern}

Set periodical ecological design goals based on the cycle period of the packaging products, the packaging ecological design is a systematic and new design pattern which combines LCA's thinking method and the packaging design, which is a design method that takes full consideration of the impact of the entire life cycle process of the packaging products on the mineral resources, biological resources, energy resources and ecological balance according to certain goal requirements, and then chooses the appropriate packaging materials and packaging plan according to the data provided by the LCA evaluation. [2] Therefore, the ecological packaging design of the ecommerce agricultural products need to take comprehensive consideration from the aspects such as the production and circulation period of the packages, the selection of materials as well as the design of the structure, the design of the packaging containers and the design of the logistics transportation and the recycling of the packages, etc, so as to find a kind of packaging design pattern suitable for the ecological development of the ecommerce products.

Design conception phase: propose a conception of the ecological packaging of the product according to the characteristics of the product, and set parameter standards for the aspects of the local agricultural products in eastern Hubei such as the packaging materials, packaging shapes, form structure, graphic representation and color selection according to the requirements of the ecological packaging design. Through the thorough market investigation, analyze the packaging materials, the production process and the expected effect, and set certain technical standard, so as to achieve the reasonable utilization of the resources on the basis of guaranteeing the basic functions of the product packaging. The principle of green design shall be respected in the visual representation and the structural form of the packaging design, and the wasting of resources and the visual pollution shall be avoided.

Production phase: use green materials or recyclable materials, the principle of saving cost and reducing pollution shall be applied in the manufacturing process so as to reduce the burden of the environment from the source. In the transport phase, the function of the packaging and the characteristics of the products shall be fully considered so as to reduce the burden of the packaging waste on the environment while protecting the commodities. It is recommended that the modularized logistics packaging shall be used during the transport phase as much as possible, which will not only save space but also facilitate the recycling of the commodities.

Consumption phase: use the green packaging idea to advocate people to form the good habit of green consumption. Recycling phase: in the terms of the recycling of the packaging of the local e-commerce agricultural products in eastern Hubei, a recycling incentive mechanism is established to encourage the consumers to participate in package recycling.

In terms of package recycling, it requires the designers to make the packaging multifunctional through reasonable packaging design. The materials of the packages of the ecommercial local agricultural products in eastern Hubei are characterized by the wear-proof and toughness, which are especially suitable for recycling. In the packaging design, combined with the living goods, explore the multiple functions of the packages, so as to reduce the pollution caused by the packaging waste. For example, tea boxes can be designed with hollow-carved pattern, which can be disassembled into a teacup mat or used as a small lampshade.

\section{B. Function-oriented Packaging Design Pattern}

In the e-commerce sales model of the local agricultural products, many products form a pattern of online and offline linkage model, and the packaging design shall be handled differently according to its functions in different situations. In the investigation of the packaging of the eastern Hubei local agricultural products, it was found that there was a lack of uniform standard for the packaging of the products. There is no packaging design specially for the e-commerce platform sales, the packages of the eastern Hubei agricultural products on the e-commerce platform are quite a mixed bag, some of the products directly adopts the packaging of the products that are sold on the shelves, 
which cannot meet the requirements of logistics packaging security level; in the e-commerce packaging of the land mark products Luotian chestnuts, the manufactures simply put the chestnuts in a net and then pack them into cartons labeled with a simple label and post them; this kind of packaging will have a negative effect on the brand image of the product and make it less competitive in the market of the similar products. Therefore, it is important to establish a function-oriented packaging design pattern, which is to design different types of e-commerce product packaging design forms according to different functions of the ecommerce product packages. Three different types of packaging design models can be established according to the different functions of the packaging of eastern Hubei agricultural products in the different segments of the ecommerce distribution channels:

The first type is the display design model at the ecommerce points of sales as well as on the shelves. With the rapid development of e-commerce industry, many products have formed a combination of online and offline sales, and many offline sales points of eastern Hubei agricultural products are established. The sales product display at the sales point is not only an important channel for consumers to experience and understand the products, but also an important window to promote and establish brand image. Therefore, the product packaging design at the points of sales is different from the logistics packaging of ecommerce products and the simple sales packaging, in addition to embodying the product characteristics in the design of the product display packaging, it also needs to highlight the brand image and achieve the purpose of brand promotion through the display of products. Therefore, the packaging design of eastern Hubei agricultural products at the e-commerce sales points shall, based on the display of brand image, integrate the product's history, regional culture and product features comprehensively and systematically. Through the refined graphics, striking colors, precise information and other elements, achieve the purpose of onsite promotion and sales. This kind of packaging design contains relatively more product information, which can represent the brand image.

The second type is a packaging design model mainly focused on the logistics function which is applicable to online sales. In the process of network sales, the promotion function of the commodities is assumed by the website and multimedia, the commodities only meet the consumers in the last link of the process of commodity circulation. Since consumers have already had a comprehensive understanding of the product information and package through the network channel in the early purchasing phase, the package of the commodity is only a container to protect the commodity to them, therefore, the design of the packages shall simplify the promotion function and strengthen the protection function.

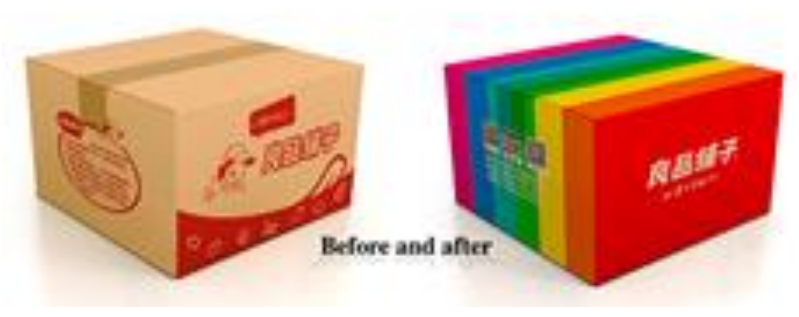

Fig. 1. New logistics packaging design of BEST ORE.

Moreover, the packaging design mode integrating transportation and sales can be adopted in the packaging design of the eastern Hubei local agricultural products that are sold online, which is to integrate the promotion and the protection functions, and through reforming the traditional packaging form, to integrate the transportation packaging and the marketing packaging to make full use of the packaging resources. Change the separation form of the transportation packaging and sales packaging, unify the two functions into one package, integrate the internal structure, external visual elements and product information of the original sales package with the logistics package, so as to ensure the transportation protection of the commodities and achieve the purpose of product publicity, which not only avoids the waste of resources caused by double packaging but also reduces environment pollution. For example in "Fig. $1 "$, the new logistics packaging design of BESTORE applies the brand image visual elements of the product to the logistics package, which also strengthens the function of product sales while protecting the products.

\section{Concise and Precise Expression Pattern of Visual Information}

In the age of information explosion, there are all kinds of commodity information both on web pages and in physical stores, the concise and clean packag ing design is no doubt a clear flow, which is very popular a mong the consumers. The display of e-commerce products mostly shows the customers with the graphics, videos and 3D animations of the products without packages, therefore, compared with traditional packaging, the packaging design of e-commerce products can be more concise. The characters, graphics, colors and other visual elements of the packages shall be intended to convey the information accurately, the representation style shall be concise, elegant and clear, and the visual pollution shall be avoided. In addition, the information can be delivered comprehensively and intuitively by means of the brand APP and QR code. "Fig. 2 " is an e-commerce packaging design for a kind of fruit, on which there is only a small amount of text information in addition to the product logo, if someone wants to know more information about the product, they can get more comprehensive product information by means of the $\mathrm{QR}$ code. This kind of concise expression technique of packaging design not only saves the packaging cost, but also avoids redundant information to cause visual fatigue to people. 


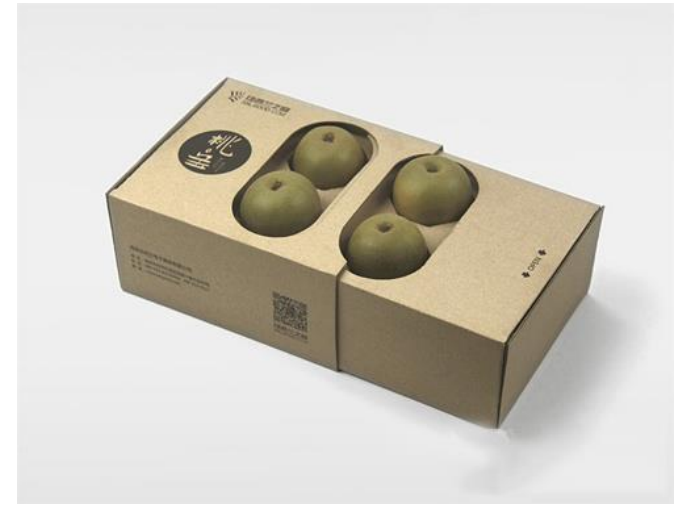

Fig. 2. The e-commerce packaging design of a kind of fruit.

\section{Generalized Packaging Design Pattern}

The packages of the e-commerce products are mainly transmitted through logistics transportation in the process of the circulation of commodities, the design of which shall be convenient for bulk product handling, transportation and management. On the market, the eastern Hubei local agricultural products are packed in different sizes and shapes, which brings great inconvenience to transportation and storage, for this reason, modular packaging design can be used to ensure the consistency of appearance structure while ensuring the difference of internal structure. That is, through comprehensively considering the size of the transportation tool, the characteristics of the products and the consumption habits of consumers, set a minimum modular volume unit based on the number of the products mostly frequently purchased and their packages, the consumers can choose the number of commodities according to the number of this modular units when buying a product, the packaging design can be multiple modular combinations, or the capacity and volume of the package can be designed by making multiple size changes based on the basic modular unit. For example, Haoyigou Department Store Co., Ltd is an e-commercial company engaged in the sales of cosmetics, this company had an annual turnover of 22 million yuan in 2011, there are 120,000 packages used in the online sales. In order to facilitate platform management and product transportation, the packaging is set as No. 6, No. 8 and No. 10 diminishing module series according to the size of the cosmetics, which classify the products of similar specifications to one model, and the products can be stabilized in the packages through the improvement of the internal structure and the design of the filler, which facilitates the platform management and reduces the cost of operations [3].

\section{CONCLUSION}

With the rapid development of e-commerce, the pattern of commodity sales is constantly updated, the packages of the e-commercial local agricultural products in eastern Hubei shall be systematically designed based on the nodes of the cycle period of the packaged products, and a ecological packaging design pattern characterized by the function-oriented, concise and precise visual information expression and generalization shall be formed, so as to reduce environmental pollution, improve the utilization rate of resources and raise brand awareness.

\section{REFERENCES}

[1] Xiao Qin, Discussion on the Packaging Ecological Design, New Arts, the second issue in 2002, 90-92;

[2] Zhou Zhong, European Eco-Packaging Movement and Its Enlightenment to China, International Exchange and Cooperation, 09 issue in 2001, 38-39.

[3] Zhan Wenyao. The Idea of Online Shopping Packaging Design Based on the Concept of Sustainable Development [J]. Ecological Economics, Academic Edition 2014(2), 164. 